\title{
Haemodynamics and oxygenation improvement induced by high frequency percussive ventilation in a patient with hypoxia following cardiac surgery: a case report
}

\author{
Alessandro Forti*, Valeria Salandin, Paolo Zanatta, Bruno Persi, Carlo Sorbara
}

\begin{abstract}
Introduction: High frequency percussive ventilation is a ventilatory technique that delivers small bursts of high flow respiratory gas into the lungs at high rates. It is classified as a pneumatically powered, pressure-regulated, time-cycled, high-frequency flow interrupter modality of ventilation. High frequency percussive ventilation improves the arterial partial pressure of oxygen with the same positive end expiratory pressure and fractional inspiratory oxygen level as conventional ventilation using a minor mean airway pressure in an open circuit. It reduces the barotraumatic events in a hypoxic patient who has low lung-compliance. To the best of our knowledge, there have been no papers published about this ventilation modality in patients with severe hypoxaemia after cardiac surgery.

Case presentation: A 75-year-old Caucasian man with an ejection fraction of 27 percent, developed a lung infection with severe hypoxaemia [partial pressure of oxygen/fractional inspiratory oxygen of 90] ten days after cardiac surgery. Conventional ventilation did not improve the gas exchange. He was treated with high frequency percussive ventilation for 12 hours with a low conventional respiratory rate (five per minute). His cardiac output and systemic and pulmonary pressures were monitored.

Compared to conventional ventilation, high frequency percussive ventilation gives an improvement of the partial pressure of oxygen from 90 to $190 \mathrm{mmHg}$ with the same fractional inspiratory oxygen and positive end expiratory pressure level. His right ventricular stroke work index was lowered from 19 to seven $\mathrm{g}-\mathrm{m} / \mathrm{m}^{2} /$ beat; his pulmonary vascular resistance index from 267 to 190 dynes.seconds $/ \mathrm{cm}^{5} / \mathrm{m}^{2}$; left ventricular stroke work index from 28 to 16 $\mathrm{gm}-\mathrm{m} / \mathrm{m}^{2} /$ beat; and his pulmonary arterial wedge pressure was lowered from 32 to $24 \mathrm{mmHg}$ with a lower mean airway pressure compared to conventional ventilation. His cardiac index $\left(2.7 \mathrm{~L} / \mathrm{min} / \mathrm{m}^{2}\right)$ and ejection fraction $(27$ percent) did not change.

Conclusion: Although the high frequency percussive ventilation was started ten days after the conventional ventilation, it still improved the gas exchange. The reduction of right ventricular stroke work index, left ventricular stroke work index, pulmonary vascular resistance index and pulmonary arterial wedge pressure is directly related to the lower respiratory mean airway pressure and the consequent afterload reduction.
\end{abstract}

\section{Introduction}

Lung injury is a well-recognized complication after operations for cardiac surgery [1]. Cardiopulmonary bypass leads to the activation of complement, neutrophils,

\footnotetext{
* Correspondence: alefortidoc@me.com
Anesthesia and Intensive Care Department, Treviso Regional Hospital, Piazza

* Correspondence: alefortidoc@me.com Ospedale No 1, 31100 Treviso, Italy
}

(c) 2010 Forti et al; licensee BioMed Central Ltd. This is an Open Access article distributed under the terms of the Creative Commons Attribution License (http://creativecommons.org/licenses/by/2.0), which permits unrestricted use, distribution, and reproduction in any medium, provided the original work is properly cited.

monocytes, macrophages, platelets and endothelial cells with secretion of cytokines, proteases, arachidonic acid metabolites and oxygen-free radicals. Leukocyte adhesion to microvascular endothelium, leukocyte extravasation and tissue damage can be seen in the final stages [2]. Major thoracic and abdominal surgery significantly reduces the respiratory reserve. Postoperative pulmonary complications, such as atelectasis and pneumonia, seem to 
be related to the disruption of the normal activity of the respiratory muscles. The disruption begins with the induction of anaesthesia and may continue into the post-operative period. Anaesthetics and drugs used in the perioperative period affect the central regulation of breathing and change the neural drive to the respiratory muscles and, in particular, to the diaphragm [3]. On the first postoperative day after a sternotomy, the observed decrease in forced vital capacity (FVC) is reported to be around $70 \%$ of the preoperative value. Ten days after surgery, when most patients can be discharged from the hospital, the FVC has increased but still remains at 30\% lower than the preoperative value [4]. It has been reported that high frequency percussive ventilation (HFPV) improves gas exchange where normal ventilation and lung recruitment therapy have failed.

HFPV VDR4 (Percussionaire Bird Technologies, ID, USA) is a ventilatory technique that delivers small bursts of high flow respiratory gas into the lung at high rates. It is classified as a pneumatically-powered, pressure-regulated, time-cycled, high-frequency flow interrupter modality of ventilation. The core of this system is the phasitron, which acts as a piston mechanism. The piston switches a high-pressure gas supply at a frequency rate of 200-1200 bpm to a low pressure rate, with high gas flow velocity.

During inspiration, lung volumes are progressively increased in a controlled, stepwise fashion by repeatedly fading subtidal volume deliveries until an oscillatory plateau is reached and maintained [5]. At the end of inspiration, the lung is allowed to empty passively until a preset expiratory base-line is reached.

It has been noted that gas exchange is as good as, if not better than, conventional ventilation (CV) at lower airway pressures. As described by Krishnan and Brower [6], there are six mechanisms that may contribute to gas exchange during all forms of high frequency ventilation: (1) direct bulk flow - the flow of inspired air in proximal alveoli leading to gas exchange by traditional methods (as with CV); (2) longitudinal dispersion is secondary to mixing from turbulent and swirling flow patterns; (3) variable flow is directed between adjacent lung regions with differences in compliance and resistance; (4) asymmetric velocity profiles - the laminar flow pattern in which gas in the centre of the airway advances inward and gas outside the centre flows in a retrograde way; (5) cardiogenic mixing - mechanical agitation from the normal heart beat, especially in peripheral lung units; and (6) molecular diffusion - the mixing of air in the smallest lung units near the alveolo-capillary membrane. HFPV is designed to be used in conjunction with mechanical ventilation or as a stand-alone treatment. This is the first case report of this ventilation modality in a patient with severe hypoxaemia after cardiac surgery.

\section{Case presentation}

A 75-year-old Caucasian man developed a lung infection with severe hypoxaemia [arterial partial pressure of oxygen $\left(\mathrm{PaO}_{2}\right)$ /fractional inspiratory oxygen $\left(\mathrm{FiO}_{2}\right)$ of 90 ] ten days after aortic valve replacement due to a severe aortic stenosis. He weighed $80 \mathrm{Kg}$ and had a body surface area of $1.98 \mathrm{~m}^{2}$, an ejection fraction (EF) of 27 percent and a history of post ischaemic dilated cardiomiopathy, severe aortic stenosis with a mean gradient of $63 \mathrm{mmHg}$, hypertension and insulin dependent diabetes mellitus there had been no alcohol or tobacco use in the last ten years. We do not have the data for the preoperative gas exchange data or the haemodynamic data; we only have the preoperatory lung function test, which shows a moderate obstructive disease.

The patient was operated via a median sternotomy. The aortic valve was replaced with a biological Hancock $21 \mathrm{~mm}$ valve. The weaning from the extracorporeal circulation (ECC) was performed with an intraortic balloon pump with a high dose of inotropic drugs (norephinefrine $0.25 \mu \mathrm{g} / \mathrm{kg} / \mathrm{min}$ and levosimendan $0.2 \mu \mathrm{g} / \mathrm{kg} / \mathrm{min}$ ). The time taken for the intervention was $260 \mathrm{~min}$ globally, including $55 \mathrm{~min}$ of aortic clamp and $125 \mathrm{~min}$ of ECC. The total fluid balance at the end of the operation was $+1000 \mathrm{~mL}$.

On the second post-operative day $\mathrm{PaO}_{2} / \mathrm{FiO}_{2}$ slowly decreased to 90 on the tenth day. We performed CV in increased pulmonary residual volume modality (Dräger Evita $\mathrm{XL}$ ) with recruitment manoeuvre, high positive end expiratory pressure (PEEP) level $\left(14 \mathrm{cmH}_{2} \mathrm{O}\right)$, low tidal volume $(6-8 \mathrm{~mL} / \mathrm{Kg})$, peak inspiratory pressure (PIP) of 38 $\mathrm{cmH}_{2} \mathrm{O}$, mean airway pressure (MArP) of $24 \mathrm{~cm} \mathrm{H} \mathrm{H}_{2} \mathrm{O}$ without any significative increase of respiratory parameter. Cardiac output, systemic and pulmonary pressures, were monitored. The patient was ventilated for four days in a pressure regulated volume controlled modality.

On days 3 and 4 we started a recruitment manoeuvre in the pressure-controlled mode at an inspiratory plateau pressure of $45 \mathrm{~cm}$ of water, a PEEP of five $\mathrm{cm}$ of water, a respiratory rate of ten breaths per minute and a 1:1 ratio of inspiration to expiration for two minutes. After the recruitment manoeuvre, PEEP at a level of 14 $\mathrm{cm}$ of water was applied. The PEEP level of $14 \mathrm{~cm}$ of water reflects the upper inflection point on the deflation limb of the pressure/volume curve and it can be used to prevent alveolar re-collapse and instability; after that we switch into pressure support ventilation but with an unsatisfactory gas exchange.

On day six we restarted with pressure regulated volume-controlled modality for two days. On days eight 
Table 1 Oxygenation and haemodynamic improvement

\begin{tabular}{llllll}
\hline & CV & HFPV after 2 hours & HFPV after 6 hours & HFPV after 12 hours & CV after HFPV \\
\hline $\mathrm{Ph}$ & 7.51 & 7.48 & 7.44 & 7.4 & 7.41 \\
$\mathrm{pCO}_{2}(\mathrm{mmHg})$ & 49 & 47 & 46 & 43 & 45 \\
$\mathrm{PaO}_{2}(\mathrm{mmHg})$ & 89 & 190 & 189 & 145 & 140 \\
$\mathrm{FiO}_{2}(\%)$ & 1 & 1 & 0.8 & 0,6 & 0.6 \\
$\mathrm{RVSWI}\left(\mathrm{g}-\mathrm{m} / \mathrm{m}^{2} /\right.$ beat $)$ & 19 & 14 & 7 & 7 & 10 \\
$\mathrm{LVSWI}\left(\mathrm{g}-\mathrm{m} / \mathrm{m}^{2} / \mathrm{beat}\right)$ & 28 & 17 & 16 & 17 & 21 \\
$\mathrm{PVRI}\left(\mathrm{d} y n e s \cdot s e c / \mathrm{cm}^{5} / \mathrm{m}^{2)}\right.$ & 267 & 190 & 192 & 195 & 240 \\
$\mathrm{PAWP}(\mathrm{mmHg})$ & 32 & 24 & 25 & 25 & 30 \\
$\mathrm{Cl}$ & 2,7 & 2,7 & 2,7 & 2,6 & 2,5 \\
\hline
\end{tabular}

$\mathrm{PaO}_{2}$ rose from 90 to $190 \mathrm{mmHg}$ with the same fractional inspiratory oxygen $\left(\mathrm{FiO}_{2}\right)$ and positive end expiratory pressure level of conventional ventilation. Right ventricular stroke work index (RVSWI) lowered from 19 to 7.

$\mathrm{g}-\mathrm{m} / \mathrm{m}^{2} /$ beat, pulmonary vascular resistance index (PVRI) from 267 to 190 dynes $\cdot \mathrm{sec} / \mathrm{cm}^{5} / \mathrm{m}^{2}$, left ventricular stroke work index (LVSWI) from 28 to $16 \mathrm{~g}-\mathrm{m} / \mathrm{m}^{2} /$ beat, pulmonary artery wedge pressure (PAWP) from 32 to $24 \mathrm{mmHg}$ with a lower mean airway pressure than conventional ventilation. Cardiac index (2.7 L/min/ $\mathrm{m}^{2}$ ) and ejection fraction (EF) of $27 \%$ did not change.

$\mathrm{CV}$, conventional ventilation; HPFV, high frequency percussive ventilation.

to ten we began bi-level positive airway pressure ventilation but it did not have an acceptable effect.

On day $11 \mathrm{HFPV}$ was started with: a $650 / \mathrm{min}$ percussive rate; a convective rate of $5 / \mathrm{min} ; 14 \mathrm{~cm} \mathrm{H}_{2} \mathrm{O}$ PEEP; $46 \mathrm{~cm} \mathrm{H} \mathrm{H}_{2} \mathrm{O}$ PIP; $2.0 \mathrm{sec}$ inspiratory time; $10.8 \mathrm{sec}$ expiratory time; $16 \mathrm{~cm} \mathrm{H} \mathrm{H}_{2} \mathrm{O}$ MArP; 1:7.0 inspiratoryexpiratory (I:E) rate of conventional ventilation; and 1:1.0 I:E rate of the micro percussive burst. After only two hours of HFPV we noted an improvement of $\mathrm{PaO}_{2}$ from 90 to $190 \mathrm{mmHg}$ with the same $\mathrm{FiO}_{2}$ and PEEP level of conventional ventilation. His right ventricular stroke work index (RVSWI) was lowered from 19 to 7 $\mathrm{g}-\mathrm{m} / \mathrm{m}^{2} /$ beat, pulmonary vascular resistance index (PVRI) from 267 to 190 dynes $\bullet \mathrm{sec} / \mathrm{cm}^{5} / \mathrm{m}^{2}$, left ventricular stroke work index (LVSWI) from 28 to $16 \mathrm{~g}-\mathrm{m} / \mathrm{m}^{2}$ / beat, pulmonary artery wedge pressure (PAWP) from 32 to $24 \mathrm{mmHg}$ with a lower MArP than with conventional ventilation. The cardiac index $\left(2.7 \mathrm{~L} / \mathrm{min} / \mathrm{m}^{2}\right)$ and ejection fraction (EF) of $27 \%$ did not change. Diuresis was always maintained between 1-1.5 mL/kg/hour. After 12

Table 2 Ventilator setting pre- and post-high frequency percussive ventilation (HFPV)

\begin{tabular}{|c|c|c|}
\hline & VGRP pre HFPV & VGRP after HFPV \\
\hline $\mathrm{TV}(\mathrm{mL})$ & 600 & 750 \\
\hline $\operatorname{MArP}\left(\mathrm{cm} \mathrm{H}_{2} \mathrm{O}\right)$ & 24 & 20 \\
\hline $\begin{array}{l}\text { Respiratory } \\
\text { rate (rate/min) }\end{array}$ & 12 & 12 \\
\hline $\mathrm{FiO}_{2}(\%)$ & 1 & 0.6 \\
\hline PEEP $\left(\mathrm{cm} \mathrm{H}_{2} \mathrm{O}\right)$ & 14 & 14 \\
\hline $\mathrm{PIP}\left(\mathrm{cm} \mathrm{H} \mathrm{H}_{2} \mathrm{O}\right)$ & 38 & 34 \\
\hline Inspiratory-expiratory rate & $1: 1.5$ & $1: 1.5$ \\
\hline
\end{tabular}

After 12 hours of HFPV, tidal volume (TV) increased from 600 to $750 \mathrm{~mL}$, mean airway pressure (MArP) lowered from 18 to $16 \mathrm{cmH}_{2} \mathrm{O}$, fractional inspiratory oxygen $\left(\mathrm{FiO}_{2}\right)$ from 1 to $0.6 \%$, peak inspiratory pressure (PIP) from 38 to $36 \mathrm{cmH}_{2} \mathrm{O}$. hours of HFPV the tidal volume increased from 600 to $750 \mathrm{~mL}, \mathrm{MArP}$ was lowered from 24 to $20 \mathrm{cmH}_{2} \mathrm{O}$, $\mathrm{FiO}_{2}$ from $1 \%$ to $0.6 \%$ and PIP from 38 to $34 \mathrm{cmH}_{2} \mathrm{O}$, with conventional ventilation. After 12 hours of HFPV we reconnected the patient to the conventional ventilation and ten hours later he was successfully extubated. Two days later he was admitted to the subintesive care unit.

We noted that HFPV (Percussionaire Bird Technologies, ID, US) improved oxygenation and it had an effect after only two hours of therapy. Reper et al. [7] show the same results in a burn patient. Another study showed better secretion clearance and outcome when using HFPV during thoracotomy [8]. Both these mechanisms improve gas exchange. Swan Ganz catheter with a Vigilance ${ }^{\odot}$ (Edward, CA, US) monitor was used to measure cardiac output and systemic and pulmonary pressures. We detected the haemodynamic and respiratory parameter after two, six and 12 hours of unconventional ventilation therapy (Tables 1, 2 and 3).

The chest X-ray (Figures 1 and 2) shows an improvement on the right lung compared to the preceding day and after only 12 hours of HFPV. Figure 3 shows the $\mathrm{PaO}_{2}$ increasing after HFPV.

Compared to conventional ventilation, HFPV gave an improved $\mathrm{PaO}_{2}$ of from 90 to $190 \mathrm{mmHg}$ after only two hours and with the same PEEP and $\mathrm{FiO}_{2}$ level as conventional ventilation. Velmahos et al. [9] reported a series of 32 adult medical and surgical intensive-care unit patients with acute lung distress syndrome who were failing with conventional ventilation (CV). In our case, the mean $\mathrm{PaO}_{2} / \mathrm{FiO}_{2}$ on $\mathrm{CV}$ was 111 , which was improved to 163 after one hour by converting to HFPV and 193 at 48 hours. PIP decreased from $42.4 \mathrm{~cm} \mathrm{H}_{2} \mathrm{O}$ on $\mathrm{CV}$ to $33.2 \mathrm{~cm} \mathrm{H} \mathrm{H}_{2} \mathrm{O}$ after one hour of HFPV and 32.5 at 48 hours, but the MArP increased from $21 \mathrm{~cm}$ 


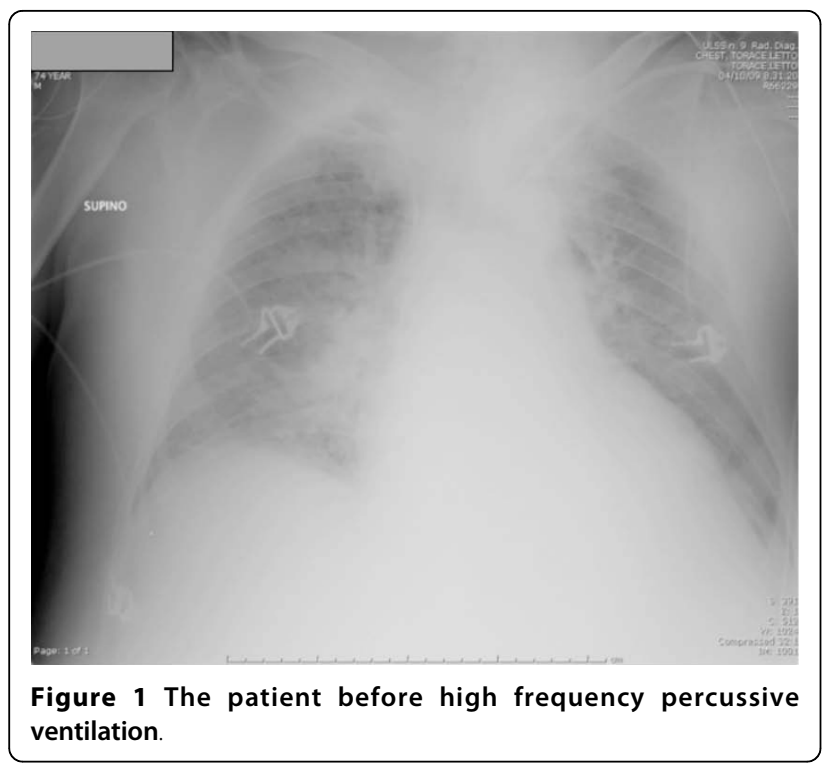

$\mathrm{H}_{2} \mathrm{O}$ on $\mathrm{CV}$ to $27 \mathrm{~cm} \mathrm{H}_{2} \mathrm{O}$ on HFPV. There was no change in haemodynamic variables. The tidal volume increased as a result of the increasing lung compliance which had been improved by the HFPV.

We found that there was a decrease in the RVSWI, LVSWI, PVRI and PAWP due to a reduction of MArP compared to the $\mathrm{CV}$ resulting in a lower afterload.

\section{Conclusion}

This case report shows the improvement in oxygenation and ventilation in a cardiac surgery patient. To the best of our knowledge, there has been no previous published report on HFPV in cardiac surgery intensive care. Lung injury is a frequent postoperative complication in such

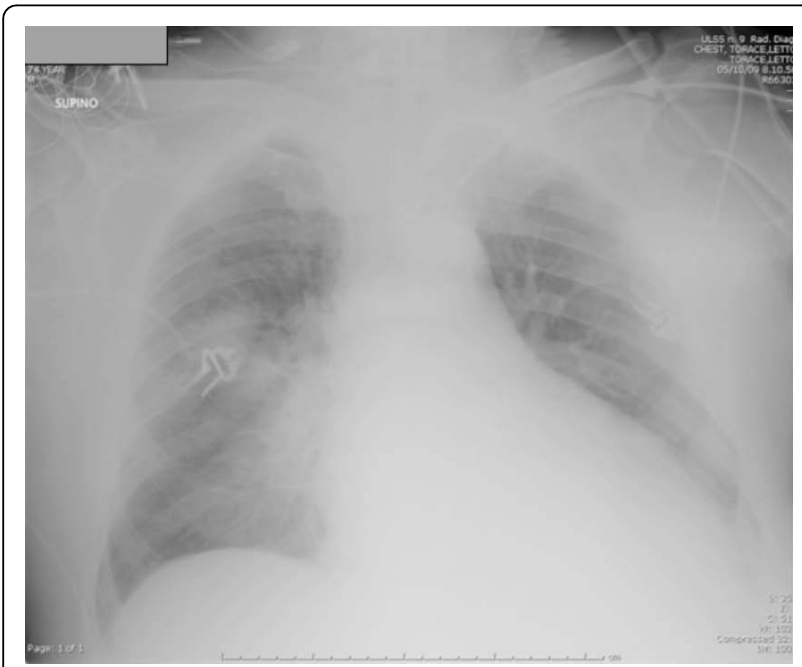

Figure 2 The patient after high frequency percussive ventilation treatment.

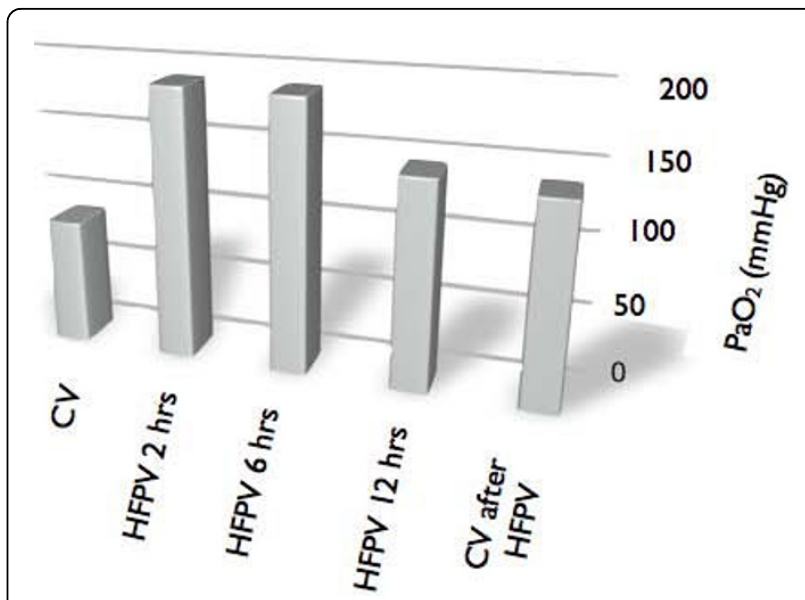

Figure 3 Arterial partial pressure of oxygen increasing after high frequency percussive ventilation treatment.

patients. HFPV is a safe ventilatory modality that improves gas exchange when $\mathrm{CV}$ does not work. In patients with an acute respiratory distress syndrome the intrathoracic pressure is greater than for a normal ventilated lung.

An augmented intrathoracic pressure increases the afterload and reduces the stroke volume of the right ventricle with an increased systolic pulmonary pressure due to an increase in the pulmonary vessels resistance. It is important to reduce the mean airway pressure and decrease the interference to the cardiac cycle.

With HFPV the mean airway pressure is lower than with conventional ventilation and so it may, therefore,

Table 3 High frequency percussive ventilation (HFPV) setting

\begin{tabular}{llll}
\hline & $\begin{array}{l}\text { HFPV post 2 } \\
\text { hours }\end{array}$ & $\begin{array}{l}\text { HFPV post } \mathbf{6} \\
\text { hours }\end{array}$ & $\begin{array}{l}\text { HFPV post 12 } \\
\text { hours }\end{array}$ \\
\hline $\begin{array}{l}\text { Percussive rate } \\
\text { (rate/min) }\end{array}$ & 650 & 650 & 650 \\
$\begin{array}{l}\text { Convective rate } \\
\text { (rate/min) }\end{array}$ & 5 & 5 & 5 \\
PEEP $\left(\mathrm{cm} \mathrm{H}_{2} \mathrm{O}\right)$ & 14 & 14 & \\
$\mathrm{PIP}\left(\mathrm{cm} \mathrm{H} \mathrm{H}_{2} \mathrm{O}\right)$ & 46 & 46 & 14 \\
$\mathrm{MArP}\left(\mathrm{cm} \mathrm{H}_{2} \mathrm{O}\right)$ & 16 & 16 & 43 \\
IT $(\mathrm{sec})$ & 2,0 & 1,9 & 13 \\
$\mathrm{ET}(\mathrm{sec})$ & 10.8 & 10.9 & 2,1 \\
I:E & $1: 7.0$ & $1: 6.9$ & 10.7 \\
i:e & $1: 1$ & $1: 1$ & $1: 7.1$ \\
$\mathrm{FiO}_{2}(\%)$ & 1 & 0.8 & $1: 1$ \\
\hline
\end{tabular}

The high peak inspiratory pressure (PIP) level does not indicate a very highpressure level, because the sample point is on the patient, directly connected with the endotracheal tube. PIPs at the carina are approximately one-third the level set on the HFPV. In the conventional ventilators the sampling point is inside the ventilator, $1.80 \mathrm{~m}$ away from the patient, the mean airway pressure (MArP) measure depends on the dissipated energy through the ventilator tubes.

PEEP, positive end expiratory pressure. 
improve the right ventricle function. More studies are required in order to confirm this data.

\section{Consent}

Written informed consent was obtained from the patient for publication of this case report and any accompanying images. A copy of the written consent is available for review by the Editor-in-Chief of this journal.

\begin{abstract}
Abbreviations
CV: conventional ventilation; EEC: extracorporeal circulation; EF: Ejection fraction; $\mathrm{FiO}_{2}$ : fractional inspiratory oxygen; HFPV: high frequency percussive ventilation; I:E: inspiratory-expiratory rate; LVSWI: left ventricular stroke work index; MArP: mean airway pressure; $\mathrm{PaO}_{2}$ : arterial partial pressure of oxygen; PAWP: pulmonary artery wedge pressure; PEEP: positive end expiratory pressure; PIP: peak inspiratory pressure; PVRI: pulmonary vascular resistance index; RVSWI: right ventricular stroke work index.
\end{abstract}

\section{Authors' contributions}

AF conceived the work, carried out the study, collected and analyzed the data and wrote the paper. PZ, VS and BP analyzed the data and helped to write the paper. CS analysed the data. All authors read and approved the final manuscript.

\section{Competing interests}

The authors declare that they have no competing interests.

Received: 5 February 2010 Accepted: 25 October 2010

Published: 25 October 2010

\section{References}

1. Ghotkar SV, Aerra V, Mediratta N: Cardiac surgery in patients with previous pneumonectomy. J Cardiothorac Surg 2008, 3:11.

2. Asimakopoulos G, Smith PL, Ratnautunga CP, Taylor KM: Lung injury acute respiratory distress syndrome after cardiopulmonary bypass. Ann Thorac Surg 1999, 68(3):1107-1115.

3. Warner DO: Preventing postoperative pulmonary complications: the role of the anesthesiologist. Anesthesiology 2000, 92(5):1467-1472.

4. Shenkman Z, Shir Y, Weiss YG, Bleiberg B, Gross D: The effects of cardiac surgery on early and late pulmonary functions. Acta Anaesthesiol Scand 1997, 41(9):1193-1199.

5. Micak R, Cortiella J, Desai M, Herndon D: Lung compliance, airway resistance, and work of breathing in children after inhalation injury. J Burn Care Rehabil 1997, 18(6):531-534.

6. Krishnan JA, Brower RG: High-frequency ventilation for acute lung injury. Chest 2000, 118(3):795-807.

7. Reper P, Van Bos R, Van Loey K, Van Laeke P, Vanderkelen A: High frequency percussive ventilation in burn patients: hemodynamics and gas exchange. Burns 2003, 29(6):603-608.

8. Lucangelo U, Antonaglia V, Zin WA, Confalonieri M, Borelli M, Columban M, Cassio S, Batticci I, Ferluga M, Cortale M, Berlot G: High-frequency percussive ventilation improves perioperatively clinical evolution in pulmonary resection. Crit Care Med 2009, 37(5):1810-1811.

9. Velmahos GC, Chan LS, Tatevossian R, Cornwell EE, Dougherty WR, Escudero J, Demetriades D: High-frequency percussive ventilation improves oxygenation in patients with ARDS. Chest 1999, 116:440-446.

doi:10.1186/1752-1947-4-339

Cite this article as: Forti et al: Haemodynamics and oxygenation improvement induced by high frequency percussive ventilation in a patient with hypoxia following cardiac surgery: a case report. Journal of Medical Case Reports 2010 4:339.

\section{Submit your next manuscript to BioMed Central and take full advantage of:}

- Convenient online submission

- Thorough peer review

- No space constraints or color figure charges

- Immediate publication on acceptance

- Inclusion in PubMed, CAS, Scopus and Google Scholar

- Research which is freely available for redistribution

Submit your manuscript at www.biomedcentral.com/submit 